Check for updates

Cite this: RSC Adv., 2018, 8, 36076

Received 9th August 2018

Accepted 17th October 2018

DOI: $10.1039 / c 8 r a 06707 d$

rsc.li/rsc-advances

\section{Chemical stability and interactions in a new antihypertensive mixture containing indapamide and dihydralazine using FT-IR, HPLC and LC-MS methods}

\author{
Anna Gumieniczek, (D) *a Justyna Galeza, ${ }^{a}$ Anna Berecka, ${ }^{a}$ Tomasz Mroczek, ${ }^{b}$ \\ Krzysztof Wojtanowski, ${ }^{b}$ Katarzyna Lipska ${ }^{a}$ and Joanna Skarbek ${ }^{a}$
}

\begin{abstract}
Indapamide and dihydralazine can be combined in fixed-dose formulations because of their complementary actions against hypertension. On the other hand, combined formulations present the problem of chemical interactions between the active ingredients, e.g. accelerated degradation of constituents or generation of quite new degradation products. Therefore, the main goal of the present study was to examine the chemical stability of indapamide and dihydralazine, as individuals and as a mixture, to detect potent interactions between both constituents, using FT-IR, HPLC and LC-MS methods. It was clearly shown that both drugs degraded more when they were in the mixture, i.e. indapamide was degraded more under high temperature/high humidity while dihydralazine was more sensitive to UV/VIS light. In solutions, indapamide was sensitive to strong acidic and strong alkaline conditions while dihydralazine degraded at $\mathrm{pH} \geq 7$. Generally, the process of degradation of indapamide and dihydralazine followed first order kinetics. The fastest degradation of both indapamide and dihydralazine was found at $\mathrm{pH} \geq 10$. Several degradation products of indapamide and dihydralazine were detected and identified by our LC-MS method. Interactions between both drugs were confirmed by detection of new degradation products of indapamide, i.e. 4-chloro-3-sulfamoylbenzamide and 4-chloro-3(formylsulfamoyl)- $\mathrm{N}$-(2-methyl-2,3-dihydro- $1 \mathrm{H}$-indol-1-yl)benzamide, only in the presence of dihydralazine.
\end{abstract}

\section{Introduction}

Indapamide is a non thiazide diuretic drug, frequently used for the treatment of hypertension all over the world. ${ }^{\mathbf{1}}$ Dihydralazine is an arterial vasodilator that reduces a resistance in arterial vessels, also used in the treatment of hypertension in Europe, the USA and China (Fig. 1).

Owing to their complementary mechanisms of action, these drugs can be combined in fixed-dose antihypertensive formulations. The purpose for using fixed-dose combinations in antihypertensive therapy is to obtain more effective control of blood pressure and enhance compliance by using a single tablet. $^{2}$ On the other hand, combined tablets present the problem of chemical interactions between the active ingredients with different chemical reactivity, e.g. accelerated degradation of one drug in the presence of another or generation of new degradation products. Therefore, the main goal of the present study was the overall assessment of chemical stability of indapamide and dihydralazine, as individuals and as a mixture,

${ }^{a}$ Department of Medicinal Chemistry, Medical University of Lublin, Jaczewskiego 4, 20-090 Lublin, Poland. E-mail: anna.gumieniczek@umlub.pl

${ }^{b}$ Department of Pharmacognosy with Medicinal Plant Unit, Medical University of Lublin, Chodźki 1, 20-093 Lublin, Poland to detect and characterize such interactions, using FT-IR, HPLC and LC-MS methods.

So far, a few HPLC methods were elaborated for determination of indapamide as an individual analyte ${ }^{3,4}$ or in the presence of other antihypertensive agents like perindopril or lisinopril, ${ }^{5-7}$ telmisartan $^{8}$ and amlodipine. ${ }^{9}$ Next three HPLC methods from the literature were described as stabilityindicating procedures, capable to determine of indapamide in the presence of its degradation products. ${ }^{10-12}$ In addition to them, a stability-indicating LC-MS method was also published. ${ }^{13}$ Also, a few papers concerning chemical stability of indapamide have been published so far. Above all, stability of indapamide was tested in a solid state at high temperature of
(A)<smiles>CC1Cc2ccccc2N1NC(=O)c1ccc(Cl)c(S(N)(=O)=O)c1</smiles>

(B)<smiles>NNc1nnc(NN)c2ccccc12</smiles>

Fig. 1 Chemical structures of indapamide (A) and dihydralazine (B). 
50-80 ${ }^{\circ} \mathrm{C}^{\mathbf{1 0 - 1 3}}$ As far as photodegradation was concerned, only standard conditions confirming photostability according to ICH Q1B guidelines ${ }^{14}$ were applied till now. ${ }^{\mathbf{1 2 , 1 3}}$ Stability of indapamide was also studied in $0.1-1 \mathrm{M} \mathrm{HCl}, 0.1-1 \mathrm{M} \mathrm{NaOH}$ and $1-10 \% \mathrm{H}_{2} \mathrm{O}_{2} \cdot{ }^{7,10-12}$ However, kinetics of degradation of indapamide has not been examined so far. Furthermore, only few HPLC methods have been reported for determination of dihydralazine alone ${ }^{15}$ or in the presence of other antihypertensive drugs like hydrochlorothiazide, ${ }^{\mathbf{1 6}}$ triamteren $^{\mathbf{1 7}}$ and clonidine. ${ }^{18}$ As far as chemical stability of dihydralazine was concerned, only one report in this area exists in the literature. ${ }^{\mathbf{1 6}}$

In the present study, indapamide and dihydralazine were degraded at high temperature/high humidity, under UV/VIS light and different $\mathrm{pH}$. Then, a FT-IR method was used for preliminary assessment of the stressed solid samples while a new validated HPLC method was applied for quantitative determination of all stressed samples, for percentage levels of degradation as well as for kinetic measurements. Finally, the degradation products of indapamide and dihydralazine were detected and characterized through our LC-MS method and some degradation pathways were proposed. At the same time, the results obtained for the stressed mixtures of indapamide and dihydralazine were compared with the results obtained for both drugs stressed as individuals, to detect and characterize chemical interactions between the drugs.

\section{Experimental}

\subsection{Materials}

Pharmaceutical grade standards of indapamide and dihydralazine sulphate from Sigma-Aldrich (St. Louis, USA), ammonium formate, formic acid, acetonitrile and methanol for LC from Merck (Darmstadt, Germany), acetic acid $\left(\mathrm{CH}_{3} \mathrm{COOH}\right)$, sodium acetate $\left(\mathrm{CH}_{3} \mathrm{COONa}\right)$, hydrochloric acid, sodium chloride $(\mathrm{NaCl})$, sodium tetraborate $\left(\mathrm{Na}_{2} \mathrm{~B}_{4} \mathrm{O}_{7}\right)$, sulphuric acid, sodium hydrogen phosphate $\left(\mathrm{NaHPO}_{4}\right)$, sodium hydroxide $(\mathrm{NaOH})$, kalium dihydrogen phosphate $\left(\mathrm{KH}_{2} \mathrm{PO}_{4}\right)$ and kalium hydroxide $(\mathrm{KOH})$ for analysis from POCh (Gliwice, Poland), acetonitrile and water for LC-MS from J. T. Baker (Center Valley, USA), Dihydralazinum ${ }^{\circledR}$ tablets $25 \mathrm{mg}$ from Pabianickie Zakłady Farmaceutyczne (Pabianice, Poland) and Indapen ${ }^{\circledR}$ tablets $2.5 \mathrm{mg}$ from Polpharma (Starogard Gdanski, Poland) were used. All buffers were prepared as described in European Pharmacopoeia $^{19}$ and have the same ionic strength of $1 \mathrm{M}$ which was attained with $4 \mathrm{M} \mathrm{NaCl}$. The $\mathrm{pH}$ measurements were done with a pH-meter HI9024C from Hanna Instruments (Padova, Italy).

\subsection{FT-IR method}

The FT-IR spectra were recorded on a Nicolet 6700 spectrometer (Thermo Scientific, USA), equipped with a Smart iTR accessory. After recording a background spectrum, the samples of approximately $2 \mathrm{mg}$ were placed on the diamond. Then, four scans were recorded for each sample over the range 4000$800 \mathrm{~cm}^{-1}$ with a resolution of $4 \mathrm{~cm}^{-1}$. The FT-IR spectra of stressed individual indapamide and dihydralazine as well as stressed binary mixtures of both drugs were compared with those obtained for the non stressed samples.

\subsection{HPLC method}

2.3.1. Chromatography. Separation was carried out on a LiChrospher®CN column $(125 \times 4.0 \mathrm{~mm}, 5 \mu \mathrm{m})$ from Merck. The column was housed in a column heater set at $22{ }^{\circ} \mathrm{C}$. The mobile phase consisted of $0.1 \%$ formic acid, $10 \mathrm{mM}$ ammonium formate and acetonitrile (55: $15: 30, \mathrm{v} / \mathrm{v} / \mathrm{v})$. The flow rate of the mobile phase was $1.4 \mathrm{~mL} \mathrm{~min}^{-1}$. Chromatography was performed with a model 306 pump with a loop Rheodyne $(20 \mu \mathrm{L})$ and a model UV170 detector from Gilson (Middleton, USA) set at $228 \mathrm{~nm}$ for quantitative measurements, and additively at 254 and $290 \mathrm{~nm}$ to detect degradation products. The system was controlled by Omnic software from Gilson.

2.3.2. Robustness. Robustness of the method was estimated changing some analytical parameters in a well-controlled way, i.e. acetonitrile content in the mobile phase $(30 \pm 2$ volumes), flow rate of the mobile phase $\left(1.4 \pm 0.2 \mathrm{~mL} \mathrm{~min}^{-1}\right)$, detection wavelength $(228 \pm 3 \mathrm{~nm})$ and column temperature (22 $\pm 2{ }^{\circ} \mathrm{C}$ ). For each set of parameters, three injections were carried

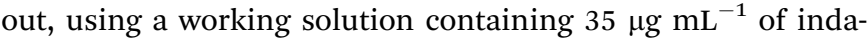
pamide and dihydralazine. Finally, the asymmetry factors and uniformity of peak areas were taken into account.

2.3.3. Linearity. Stock solutions of indapamide and dihydralazine ( $1 \mathrm{mg} \mathrm{mL}^{-1}$ ) were used to obtain the working solutions of the drugs in the range from 10 to $60 \mu \mathrm{g} \mathrm{mL}{ }^{-1}$. Then, six injections were made onto the column for each concentration. The obtained peak areas were plotted against the corresponding concentration of the drugs to construct the calibration equations. The limit of detection (LOD) and the limit of quantification (LOQ) were determined from the standard deviation of the intercepts and slopes of the calibration lines, using 3.3 and 10 factors for LOD and LOQ, respectively.

2.3.4. Precision and accuracy. Precision was determined analyzing the working solutions containing 15,35 and $55 \mu \mathrm{g} \mathrm{mL}$ of indapamide and dihydralazine, three times during the same day and then on three subsequent days. Accuracy was estimated determining both active substances in the samples of powdered tablets and comparing the determined amounts to the nominal values. The weighed portions of powdered tablets containing $3 \mathrm{mg}$ of indapamide and $3 \mathrm{mg}$ of dihydralazine were transferred to $25 \mathrm{~mL}$ volumetric flasks with $\mathrm{ca} .15 \mathrm{~mL}$ of methanol, sonicated for $30 \mathrm{~min}$, diluted to the mark and filtered by nylon membrane filters $(0.45 \mu \mathrm{m})$. Then, $2.5 \mathrm{~mL}$ volumes were diluted to $10 \mathrm{~mL}$ and injected onto the column. The assay was repeated six times, individually weighing the respective portions of powdered tablets. The concentrations of indapamide and dihydralazine were calculated using respective calibration equations and finally expressed as RSD for precision and percentage recovery for accuracy.

\subsection{Degradation in a solid state}

Solid mixtures containing indapamide and dihydralazine were prepared by weighing equal amounts of individual substances and mixing them thoroughly in an agate mortar. Then, portions of individual substances and their mixtures were placed in standardized small flat vessels so that the thickness of the layer was approximately $3 \mathrm{~mm}$. The samples were placed in a climate chamber KBF P240 from Binder (Neckarsulm, Germany) set at 
$70{ }^{\circ} \mathrm{C} / 80 \% \mathrm{RH}$ for 2 months. This part of experiment was performed according to ICH Q1A(R2) guidelines. ${ }^{20}$ Similar samples were placed in a Suntest CPS Plus chamber from Atlas (Linsengericht, Germany) and exposed to UV/VIS light in the range 300-800 nm, with energy equal $18902 \mathrm{~kJ} \mathrm{~m}^{-2}, 56706 \mathrm{~kJ} \mathrm{~m}^{-2}$ and $113412 \mathrm{~kJ} \mathrm{~m}^{-2}$. Energy of $18902 \mathrm{~kJ} \mathrm{~m}^{-2}$ was equivalent to 1.200.000 lux $\mathrm{h}$ and $200 \mathrm{~W} \mathrm{~m}^{-2}$ that is recommended by $\mathrm{ICH}$ Q1B guidelines ${ }^{\mathbf{1 4}}$ as a dose of light that confirms drug photostability. During whole experiment, temperature in the chamber did not exceed $35^{\circ} \mathrm{C}$.

After irradiation, the amounts of $10 \mathrm{mg}$ of individual substances or $20 \mathrm{mg}$ of the mixtures were weighed and dissolved with methanol to obtain solutions of concentration $1.0 \mathrm{mg} \mathrm{mL} \mathrm{m}^{-1}$, for both indapamide and dihydralazine. After diluting with methanol to cover the linearity range, the solutions were analyzed using our HPLC method. The procedure was repeated three times for each sample and the concentrations of non degraded (remaining after degradation) indapamide and dihydralazine were calculated from the linear calibration equations. At the same time, percentage levels of degradation of indapamide and dihydralazine were calculated taking into account their starting concentrations.

\subsection{Degradation in solutions}

2.5.1. Kinetics. From the stock solutions of indapamide and dihydralazine ( $\left.2 \mathrm{mg} \mathrm{mL}^{-1}\right), 1 \mathrm{~mL}$ volumes were dispensed to small glass tubes from Medlab (Raszyn, Poland) (individually stressed drugs). From the stock solutions of indapamide and dihydralazine ( $4 \mathrm{mg} \mathrm{mL}{ }^{-1}$ ), $0.5 \mathrm{~mL}$ volumes were dispensed in similar way and mixed together (the mixtures). To each tube, $1 \mathrm{~mL}$ volumes of appropriate stressor ( $1 \mathrm{M} \mathrm{HCl}, 1 \mathrm{M} \mathrm{NaOH}$, buffers of $\mathrm{pH} 4,7$ and 10) were added. The tubes were tightly closed with stoppers and placed in a thermostated $\left( \pm 1^{\circ} \mathrm{C}\right)$ water bath from WSL (Warszawa, Poland) set at $80{ }^{\circ} \mathrm{C}$. The samples were removed from the bath after subsequently 15, 30, 45, 60, 75, 90, 105, 120, 135, 150, 165, 180, 195, 210, 225, 240, 255, 270, 285 and $300 \mathrm{~min}$. They were immediately cooled and neutralized if necessary. After diluting with methanol to covering the linearity range, each sample was analyzed using our HPLC method. The procedure was repeated three times for each sample, and the concentrations of non degraded (remaining after degradation) indapamide and dihydralazine were calculated from respective calibration equations. When the level of degradation was at least $10 \%$ during $300 \mathrm{~min}$, kinetic parameters were calculated. The logarithm of the concentration of non degraded indapamide and dihydralazine was plotted against time of degradation, to obtain the equations $y=a x$ $+b$ and $R^{2}$ coefficients. Then further kinetic parameters, i.e. degradation rate constant $(k)$ and degradation time of $50 \%$ substance $\left(t_{0.5}\right)$ were calculated. At the same time, percentage levels of degradation of indapamide and dihydralazine in different $\mathrm{pH}$ were calculated taking into account their starting concentrations.

2.5.2. Photodegradation in solutions. Equal volumes of $2 \mathrm{~mL}$ of the stock solutions of indapamide and dihydralazine ( $2 \mathrm{mg} \mathrm{mL} \mathrm{m}^{-1}$ ) were dispensed to standardized quartz glass stoppered dishes (individually stressed drugs). Equal volumes of $1 \mathrm{~mL}$ of the stock solutions of indapamide and dihydralazine (4 mg
$\mathrm{mL}^{-1}$ ) were mixed in the same dishes to obtain the mixtures. The samples were placed in a Suntest CPS Plus chamber and exposed to UV/VIS light in the range $300-800 \mathrm{~nm}$, with energy equal $18902 \mathrm{~kJ} \mathrm{~m}^{-2}, 56706 \mathrm{~kJ} \mathrm{~m}^{-2}$ and $113412 \mathrm{~kJ} \mathrm{~m}^{-2}$ while temperature in the chamber did not exceed $35{ }^{\circ} \mathrm{C}$. After irradiation, the solutions were diluted with methanol to cover the linearity range and analyzed by means of our HPLC method. The procedure was repeated three times for each sample, and the concentrations of non degraded (remaining after degradation) indapamide or dihydralazine were calculated from the linear calibration equations. At the same time, percentage levels of degradation of indapamide and dihydralazine were calculated taking into account their starting concentrations.

\subsection{LC-MS method}

The samples were analyzed with a 6530B accurate-mass-QTOFMS spectrometer with a dual ESI-Jet Stream ion source, using an Eclipse XDB C18 $(150 \times 4.6 \mathrm{~mm}, 3.5 \mu \mathrm{m})$ column from Agilent Technologies (Santa Clara, USA). The chromatograph was equipped with a DAD, an autosampler, a binary gradient pump, and a column oven. The mobiles phases were: acetonitrilewater $(1: 99, \mathrm{v} / \mathrm{v})$ with $10 \mathrm{mM}$ ammonium formate $(0.1 \%)$ (solvent A) and acetonitrile-water (95:5, v/v) with $10 \mathrm{mM}$ ammonium formate $(0.1 \%)$ (solvent B). Following elution procedure was used: $0-60 \mathrm{~min}, 0-95 \%$ of solvent B with a stable flow rate $0.4 \mathrm{~mL} \mathrm{~min}^{-1}$. The injection volume for the samples was $10 \mu \mathrm{L}$. The analysis was conducted at $25{ }^{\circ} \mathrm{C}$.

Following parameters of the ion source were applied: a negative ion mode (-ESI), gas $\left(\mathrm{N}_{2}\right)$ flow rate $12 \mathrm{~L} \mathrm{~min}{ }^{-1}$, nebulizer pressure $35 \mathrm{psig}$, vaporizer temperature $350{ }^{\circ} \mathrm{C}$, sheath gas temperature $400{ }^{\circ} \mathrm{C}$, sheath gas $\left(\mathrm{N}_{2}\right)$ flow $12 \mathrm{~L} \mathrm{~min}^{-1}$, $\mathrm{m} / \mathrm{z}$ range 100-1000 mass units with an acquisition mode auto MS/MS, collision induced dissociation (CID) 10 and $40 \mathrm{eV}$ with MS scan rate of 1 spectrum $\mathrm{s}^{-1}$ and 2 spectra per cycle, VCap $4000 \mathrm{~V}$, skimmer $65 \mathrm{~V}$, fragmentor $150 \mathrm{~V}$ and Octopole RF Peak $750 \mathrm{~V}$. Additionally, the analysis was made in auto MS/MS with excluded $\mathrm{m} / \mathrm{z}$ at 966.0007 and $\mathbf{1 1 2 . 9 8 5 6}$ for negative ion mode, corresponding to the $\mathrm{m} / \mathrm{z}$ of reference ions.

Before LC-MS analysis, acetate, phosphate and borate buffers were removed from the stressed samples by the means of Bakerbond SPE C8 disposable extraction columns $(3 \mathrm{~mL})$ from J. T. Baker using a UCT Positive Pressure Manifold station (Horsham, USA). The ions were removed from the bed with water while the substances of interest (indapamide, dihydralazine and their degradation products) were eluted with methanol. Respective fractions were pooled, dried under vacuum and finally reconstituted with acetonitrile.

\section{Results and discussion}

\subsection{FT-IR analysis of the stressed samples}

FT-IR spectrum of pure indapamide showed significant bands at 3310 and $3207 \mathrm{~cm}^{-1}$ due to $\mathrm{N}-\mathrm{H}$ stretching, at $1649 \mathrm{~cm}^{-1}$ due to $\mathrm{C}=\mathrm{O}$ stretching, at $1597 \mathrm{~cm}^{-1}$ due to aromatic $\mathrm{C}-\mathrm{H}$ stretching, and at 1380 and $1166 \mathrm{~cm}^{-1}$ due to $\mathrm{SO}_{2}$ stretching 
(A)

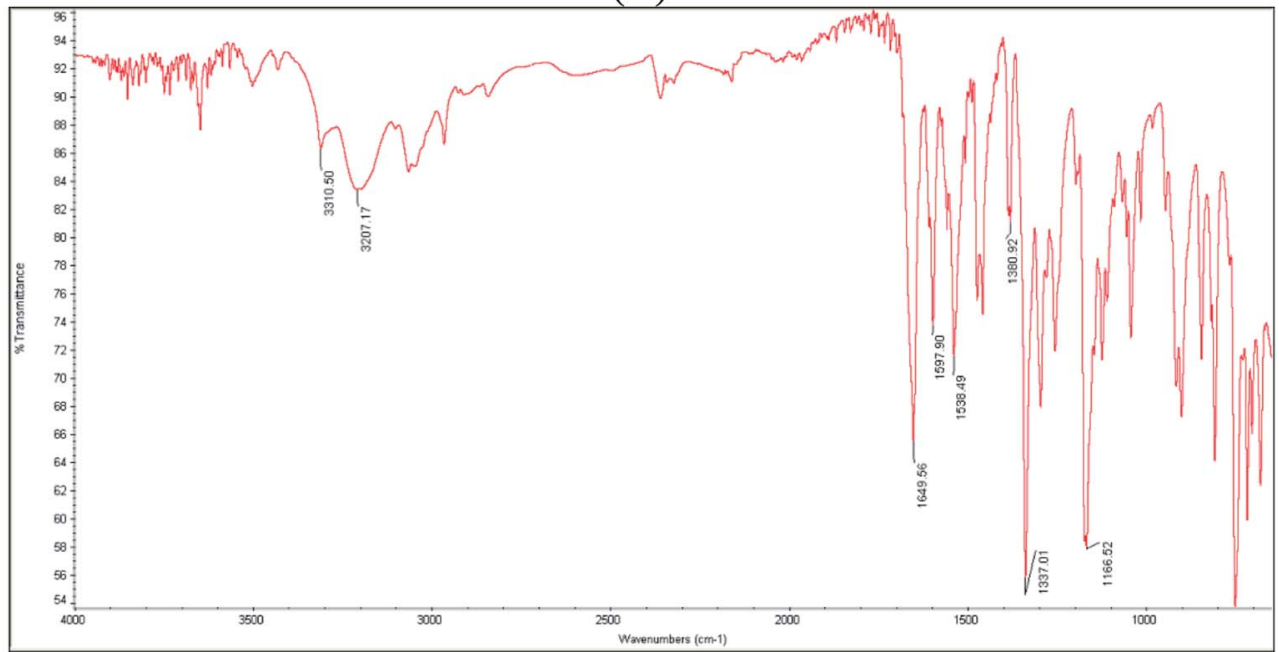

(B)

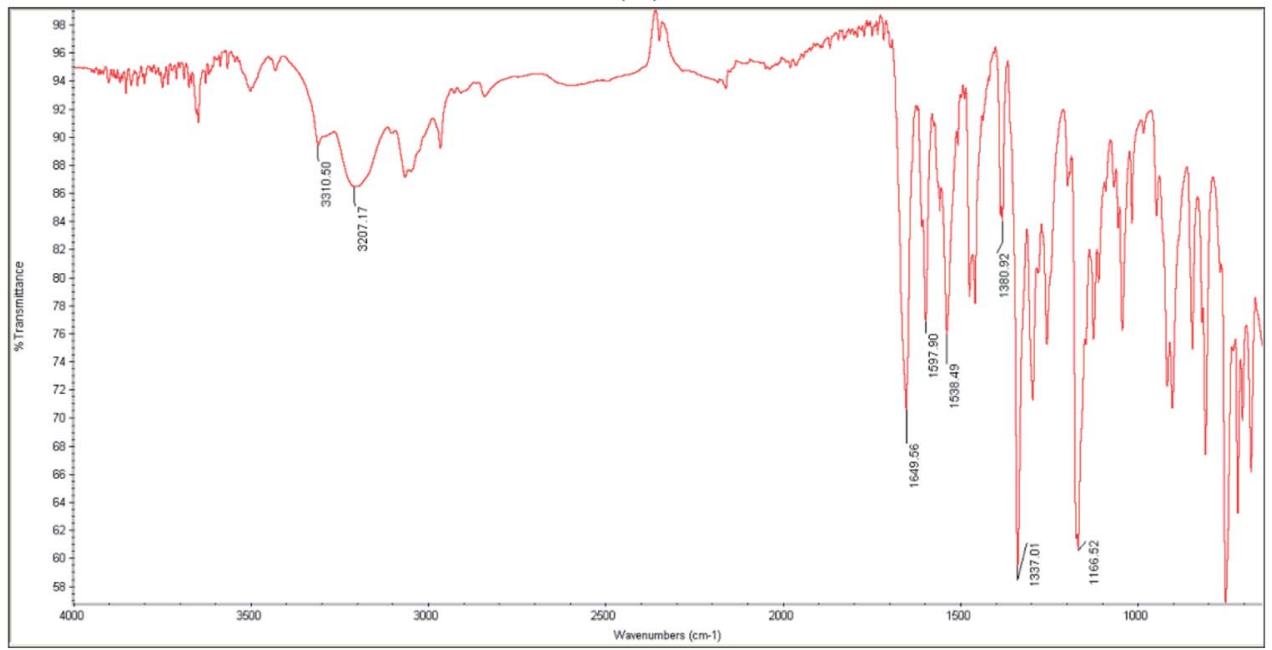

(C)

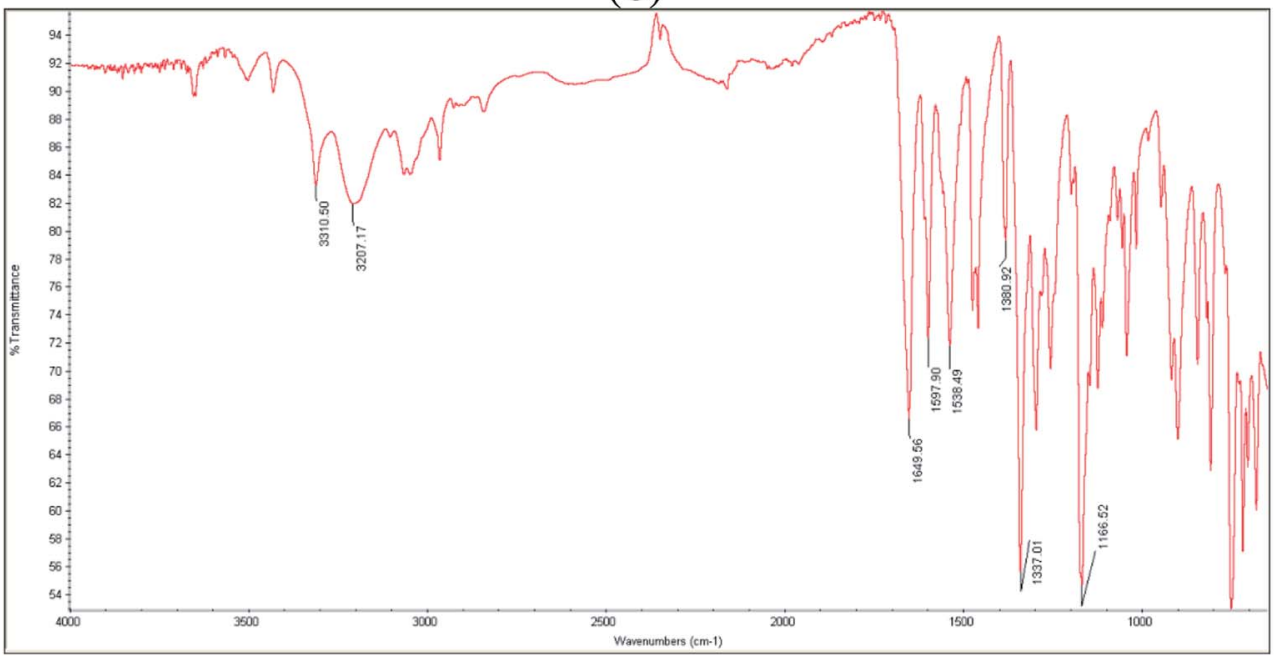

Fig. 2 FT-IR spectra of pure indapamide (A); indapamide stressed at high temperature/high humidity (B); indapamide stressed under UV/VIS light (C).

vibrations. In addition, characteristic bands at 1538 and $1337 \mathrm{~cm}^{-1}$ were clearly seen (Fig. 2A).

FT-IR spectrum of pure dihydralazine showed significant bands at $3310 \mathrm{~cm}^{-1}$ corresponding to $\mathrm{N}-\mathrm{H}$ stretching and at
$1590 \mathrm{~cm}^{-1}$ due to aromatic C-H stretching vibrations. In addition, characteristic bands at 1368, 1189, and $1055 \mathrm{~cm}^{-1}$ were clearly seen (Fig. 3A). 
(A)

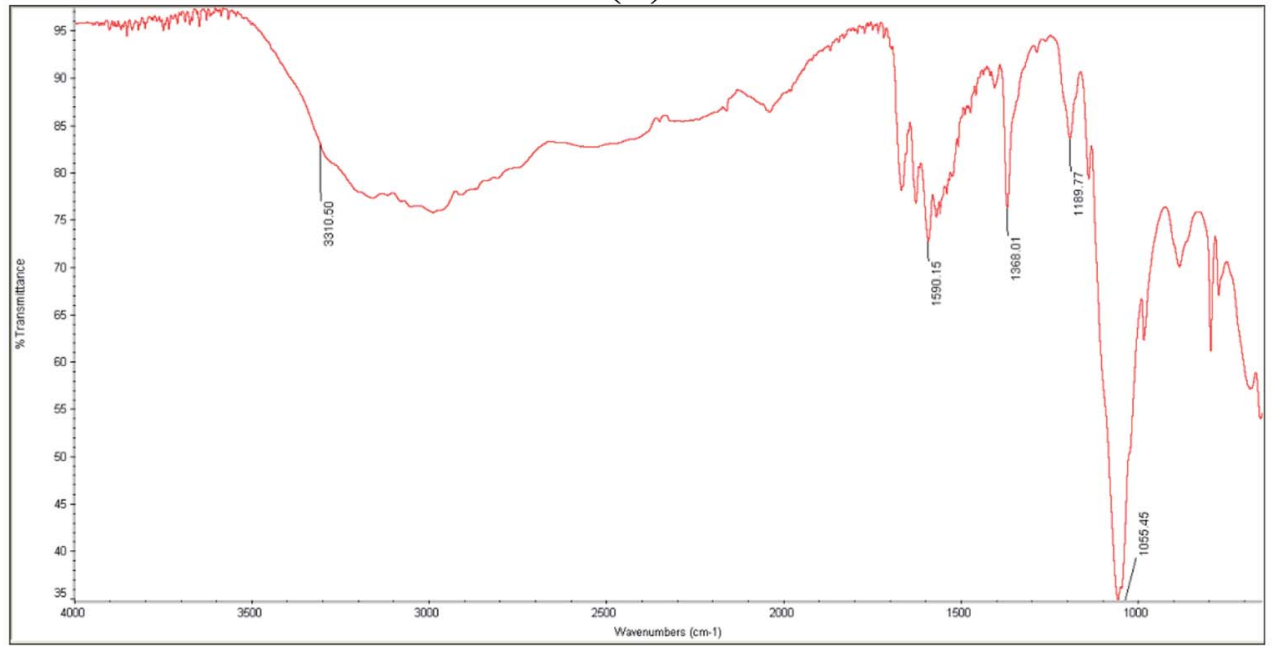

(B)

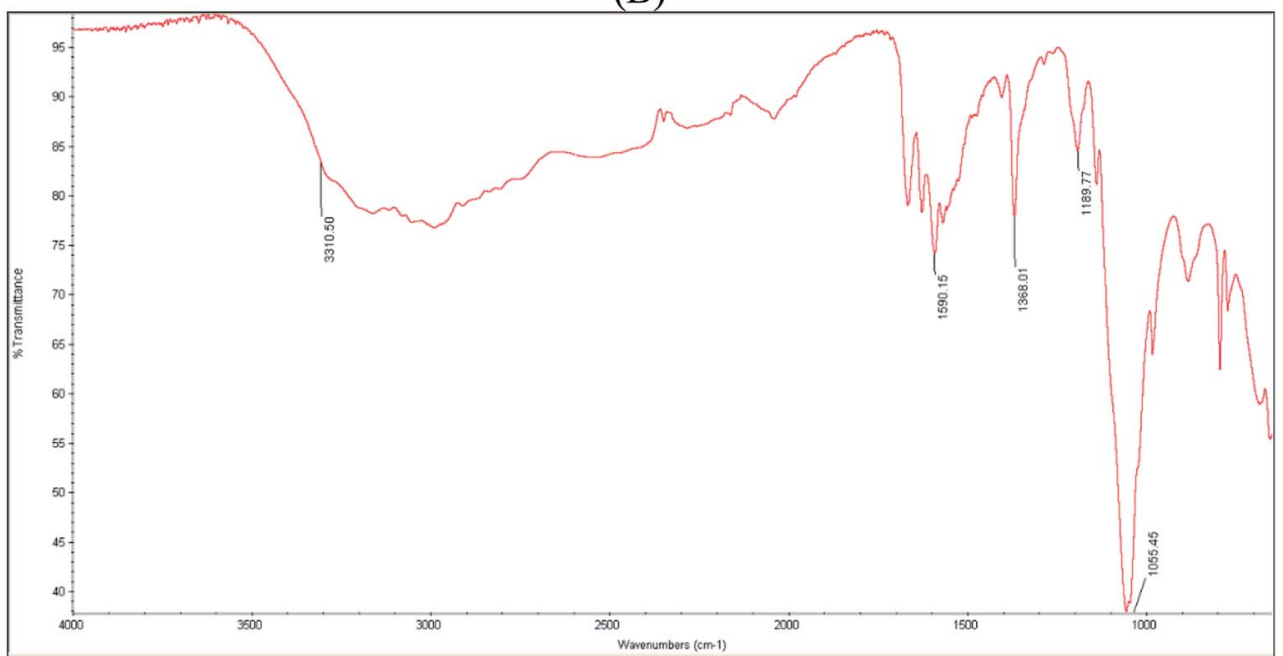

(C)

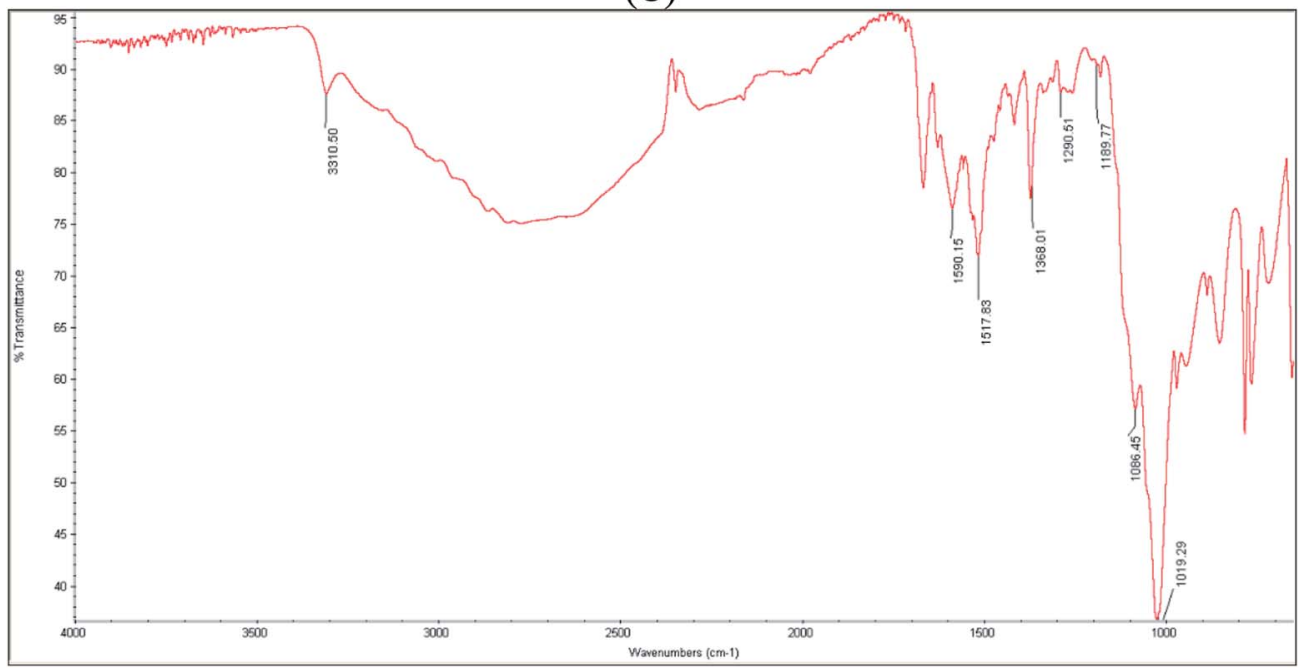

Fig. 3 FT-IR spectra of pure dihydralazine (A); dihydralazine stressed at high temperature/high humidity (B); dihydralazine stressed under UV/VIS light (C).

The spectrum of individual indapamide did not change after degradation at high temperature/high humidity (Fig. 2B) and under UV/VIS light (Fig. 2C), similarly as the spectrum of individual dihydralazine affected by high temperature/high humidity (Fig. 3B). However, the spectrum of individual dihydralazine affected by UV/VIS light showed visible changes 
Table 1

Products of degradation of indapamide and dihydralazine identified using our LC-MS method

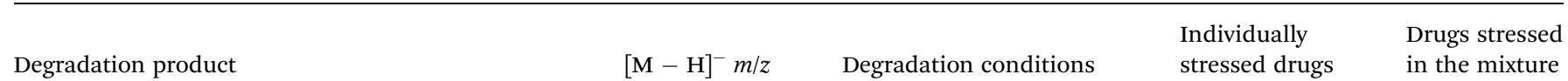<smiles>NC(=O)c1ccc(Cl)c(S(N)(=O)=O)c1</smiles>

4-Chloro-3-sulfamoylbenzamide<smiles>Cc1cc2ccccc2n1NC(=O)c1ccc(Cl)c(S(N)(=O)=O)c1</smiles>

4-Chloro- $N$-(2-methyl-1 $H$-indol-1-yl)3-sulfamoylbenzamide (impurity B)<smiles>CC1(C)Cc2ccccc2N1NC(=O)c1ccc(Cl)c(S(=O)(=O)NC=O)c1</smiles>

4-Chloro-3-(formylsulfamoyl)- $N$-(2-methyl2,3-dihydro-1 $H$-indol-1-yl)-3-benzamide<smiles>NNCc1ccccc1</smiles>

Phenylmethylhydrazine<smiles>N/N=C1\NNCc2ccccc21</smiles>

1-Hydrazinophthalazine<smiles>N/N=C1\N=N/C(=N\N)c2ccccc21</smiles>

1,4-Dihydrazinylidenophthalazine
232.98

362.04
-UV/VIS (solid)

\section{$-1 \mathrm{M} \mathrm{HCl}$}

-Borate buffer (pH 10)

-UV/VIS (solution)

$-70{ }^{\circ} \mathrm{C} / 80 \% \mathrm{RH}$ (solid)

-UV/VIS (solid)

$-1 \mathrm{M} \mathrm{HCl}$

$-1 \mathrm{M} \mathrm{NaOH}$

-Acetate buffer (pH 4)

-Phosphate buffer (pH 7)

-Borate buffer (pH 10)

-UV/VIS (solution)

-Borate buffer ( $\mathrm{pH}$ 10)

-UV/VIS (solid)

-Borate buffer (pH 10)

-UV/VIS (solution)

-UV/VIS (solid)

-Borate buffer (pH 10

-UV/VIS (solution) 
(A)

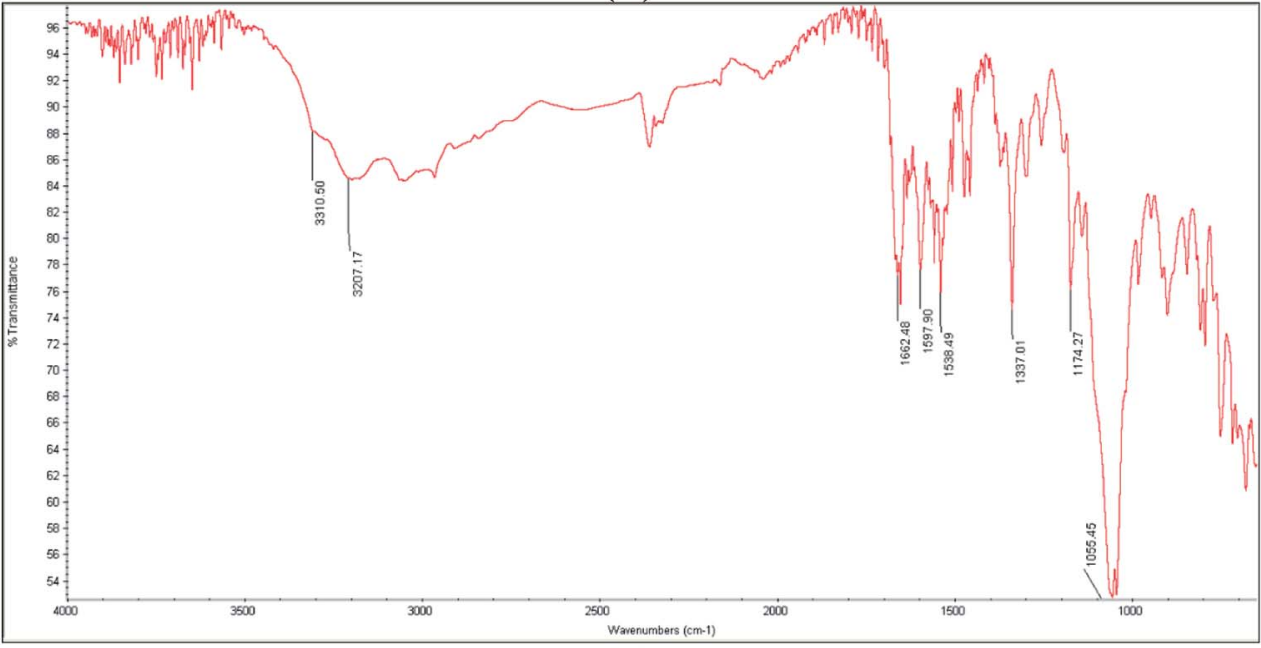

(B)

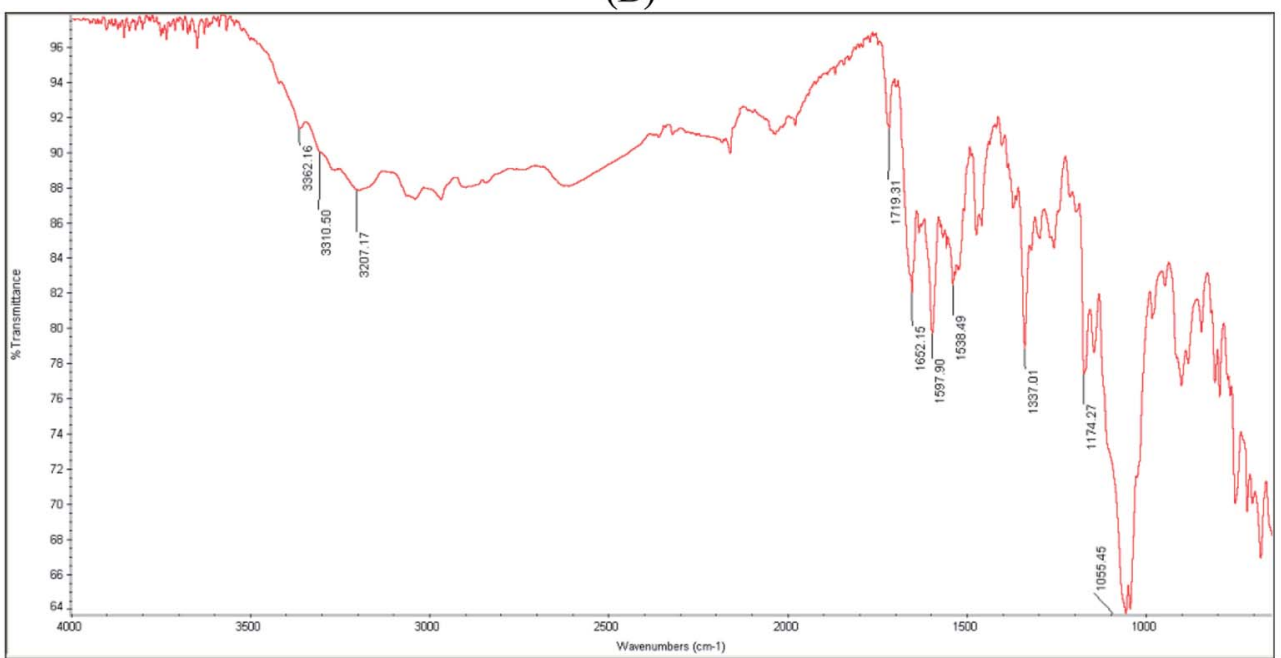

(C)

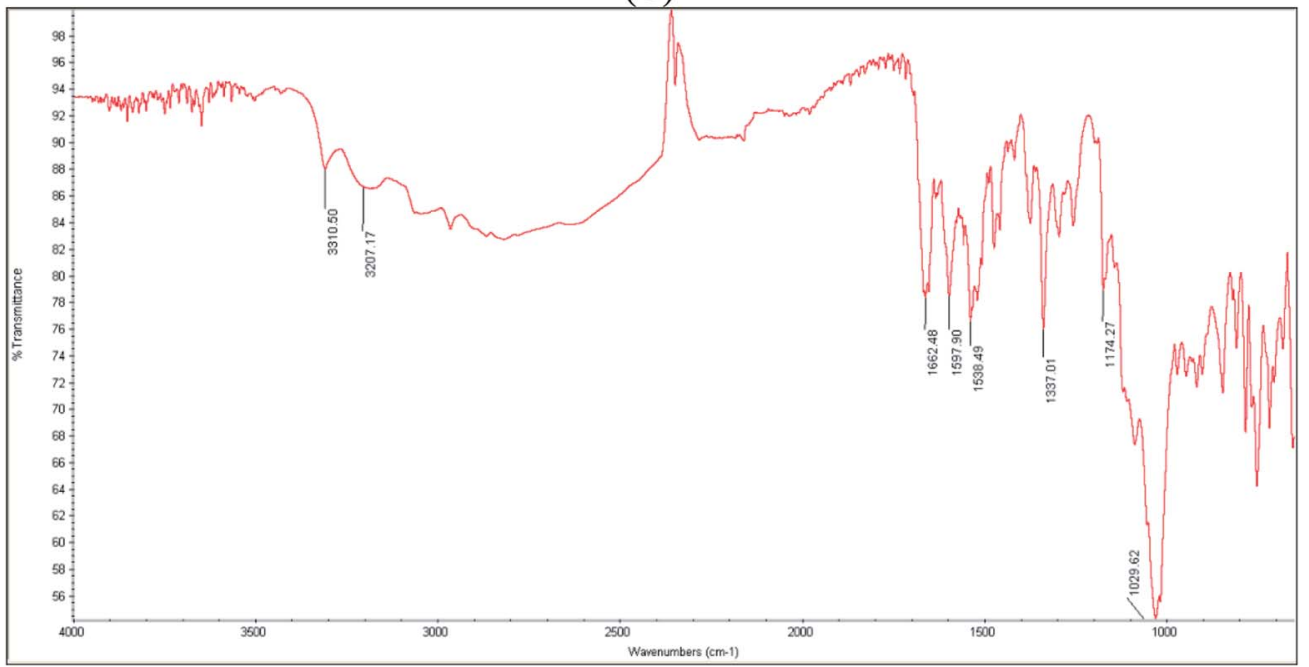

Fig. 4 FT-IR spectra of non stressed mixture of indapamide with dihydralazine (A); the mixture stressed at high temperature/high humidity (B); the mixture stressed under UV/VIS light (C).

as compared to the standard spectrum, i.e. broadening the band at $1590 \mathrm{~cm}^{-1}$ together with appearing of new bands at 1517,1290 and $1086 \mathrm{~cm}^{-1}$. At the same time, a broad band at
$1055 \mathrm{~cm}^{-1}$ deteriorated to $1019 \mathrm{~cm}^{-1}$ (Fig. 3C). In addition, the same sample analyzed by means of our LC-MS method showed the presence of new degradation products of dihydralazine 
formed by loss of hydrazine and breaking phenazine ring (Table 1).

The spectrum of the mixture of indapamide and dihydralazine showed overlapping of their bands at $3310 \mathrm{~cm}^{-1}$ due to $\mathrm{N}-\mathrm{H}$ stretching vibrations, overlapping a band of indapamide at $1597 \mathrm{~cm}^{-1}$ with that of dihydralazine at $1590 \mathrm{~cm}^{-1}$ due to aromatic $\mathrm{C}-\mathrm{H}$ stretching vibrations, overlapping a band of indapamide at $1166 \mathrm{~cm}^{-1}$ with that of dihydralazine at $1189 \mathrm{~cm}^{-1}$ to form a new band at $1174 \mathrm{~cm}^{-1}$, as well as decreasing a band of indapamide at $3207 \mathrm{~cm}^{-1}$ and that of dihydralazine at $1368 \mathrm{~cm}^{-1}$. In addition, a band of indapamide at $1649 \mathrm{~cm}^{-1}$ due to $\mathrm{C}=\mathrm{O}$ stretching vibrations deteriorated to $1662 \mathrm{~cm}^{-1}$ (Fig. 4A).

Even more visible changes were detected in respective spectra after stress degradation. At the spectrum of the mixture stressed by high temperature/high humidity, a new band at $1719 \mathrm{~cm}^{-1}$ appeared while a band at $1662 \mathrm{~cm}^{-1}$ deteriorated to $1652 \mathrm{~cm}^{-1}$ (Fig. 4B). However, our LC-MS experiments for this sample did not show new degradation products of indapamide or dihydralazine (Table 1). When the mixture was affected by UV/VIS light, the most significant changes were observed as disappearing a band at $1174 \mathrm{~cm}^{-1}$ and changing the shape of a broad band in the range $1100-950 \mathrm{~cm}^{-1}$ (Fig. 4C). Therefore, we supposed that photo-induced interactions between indapamide and dihydralazine were different than those caused by high temperature/high humidity. At the same time, our LC-MS experiments for these samples resulted as identification of new degradation product of indapamide formed by loss of 2-methyl$1 H$-indole (Table 1 ).

\subsection{Identification of degradation products by LC-MS method}

Using negative ionization mode (ESI) to indapamide standard, a deprotonated molecule $[\mathrm{M}-\mathrm{H}]^{-}$of $m / z 364.05$ was obtained which followed a parallel fragmentation pathway. Firstly, after losing 2-methyl-2,3-dihydro-1 $H$-indole, an ion of $\mathrm{m} / \mathrm{z} 232.98$ was formed. Its further fragmentation led to formation of an ion of $\mathrm{m} / \mathrm{z} 153.00$ (loss of sulfonamide group) or ions of $\mathrm{m} / \mathrm{z} 188.97$ (loss of amide group) and 77.97 (loss of chlorobenzene). Secondly, from a deprotonated molecule of indapamide of $\mathrm{m} / \mathrm{z}$ 364.05 , an ion of $m / z 132.08$ was formed, after losing 4-chloro-3sulfamoylbenzamide (Fig. 5). These results are consistent with previous results from the literature concerning fragmentation of indapamide with negative ESI. ${ }^{13}$

The monograph of indapamide in European Pharmacopoeia ${ }^{19}$ lists two impurities, i.e. 2-methyl-1-nitroso-2,3-dihydro$1 H$-indole (impurity A) and 4-chloro- $N$-(2-methyl- $1 H$-indol-1-yl)3-sulfamoylbenzamide (impurity B). In the present study, the main degradation product of indapamide was detected as a fragment ion of $m / z 362.04$ and identified as impurity B. It was detected in all stressed samples (Table 1). Thus, our results confirmed those obtained previously by El-Gindy et $a .^{10}$ and Jogia et al. ${ }^{12}$ who detected impurity B as a result of acid, base and photo-induced degradation of indapamide.

When dihydralazine standard was fragmented using negative ESI mode, a deprotonated molecule $[\mathrm{M}-\mathrm{H}]^{-}$of $m / z 189.09$ was formed. Then, fragment ions of $m / z 161.08$ and 118.07 were

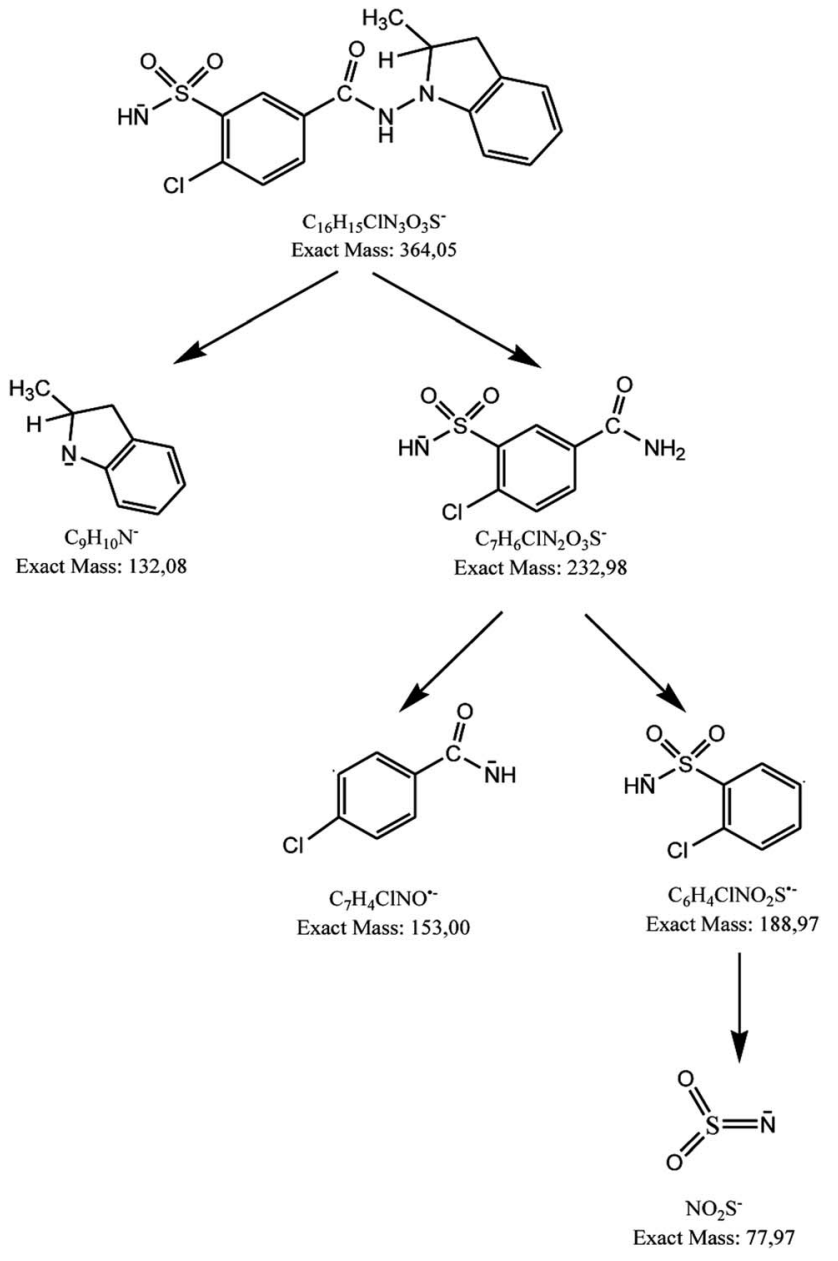

Fig. 5 Fragmentation pattern of indapamide in negative ionization mode: CID off set $10 \mathrm{~V}$.

produced. So, we concluded for a second time that dihydralazine fragmented by loss of hydrazine and breaking phenazine ring. ${ }^{16}$ In our LC-MS studies, products of $\mathrm{m} / \mathrm{z} 121.03$ and 161.04 were detected after degradation in buffer of $\mathrm{pH} 10$ and under UV/VIS light (in a solid state and in methanolic solutions). They were identified as phenylmethylhydrazine and 1hydrazinophthalazine. Furthermore, next product of degradation of dihydralazine in $1 \mathrm{M} \mathrm{NaOH}$ of $m / z 187.04$ was detected and identified as 1,4-dihydrazinylidenophthalazine (Table 1). Two of these compounds, i.e. phenylmethylhydrazine and 4dihydrazinylidenophthalazine were described for the first time in our last paper. ${ }^{16}$

When the stressed mixtures of indapamide and dihydralazine were examined, fragment ions of $m / z$ 121.03, 161.04 and 187.04 from dihydralazine (after degradation in borate buffer of pH 10, $1 \mathrm{M} \mathrm{NaOH}$ and under UV/VIS light), as well as of $\mathrm{m} / \mathrm{z} 362.04$ from indapamide (after degradation in all conditions) were detected. In addition, quite new product of degradation of indapamide was detected as a fragment ion of $\mathrm{m} / \mathrm{z}$ 232.98, as a result of degradation in $1 \mathrm{M} \mathrm{HCl}$, borate buffer of pH 10 and under UV/VIS light (in solid state and in methanolic solution). This compound was identified as 4-chloro-3sulfamoylbenzamide (Table 1). Respective LC-DAD 
(A)

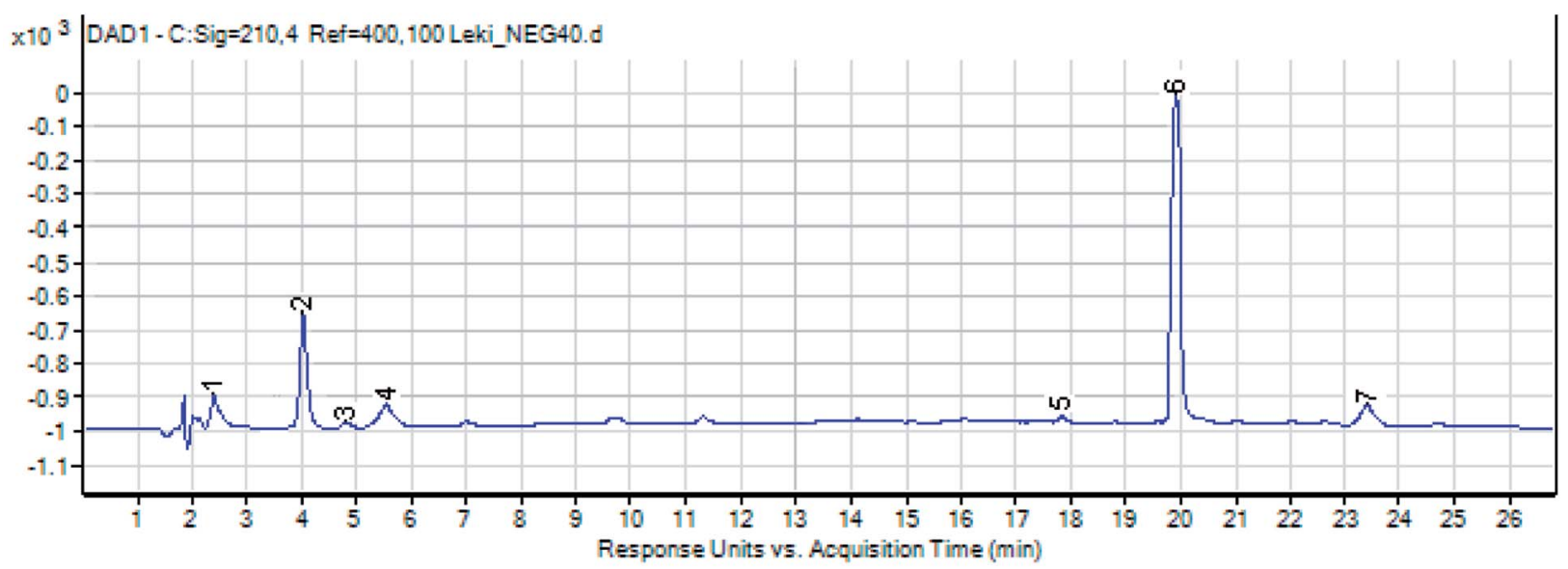

(B)

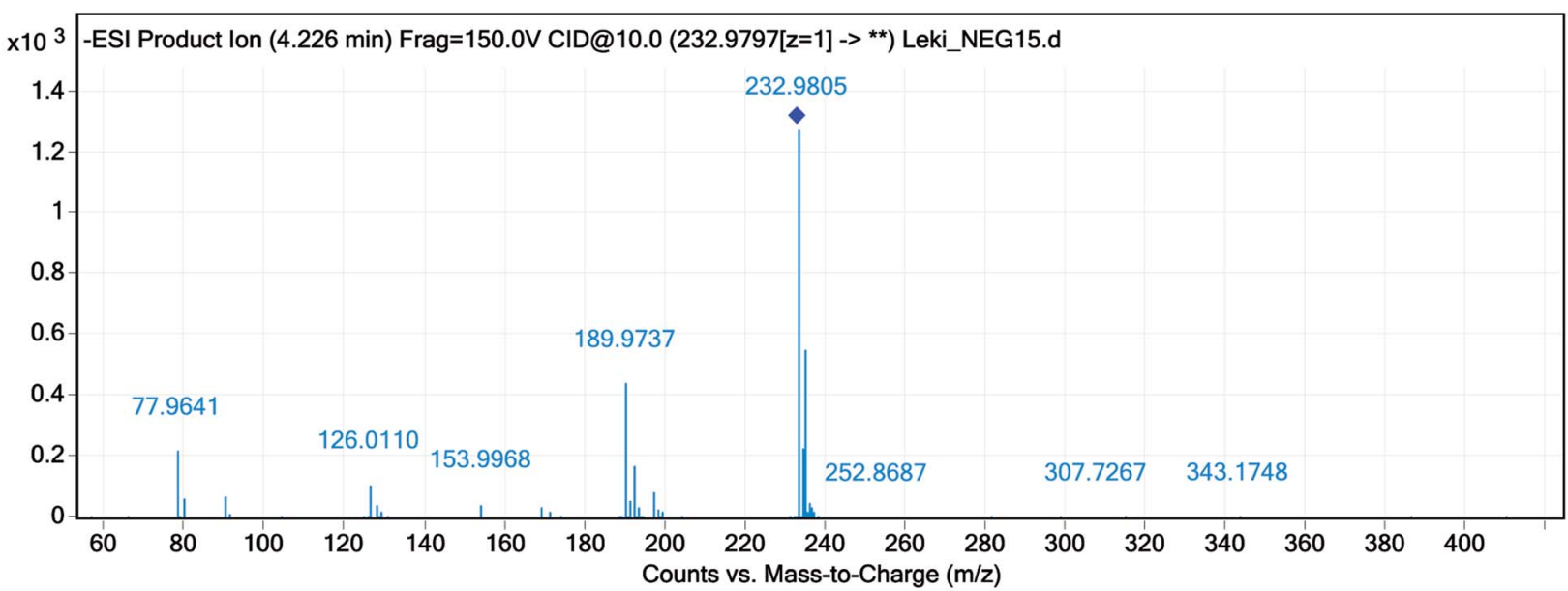

(C)

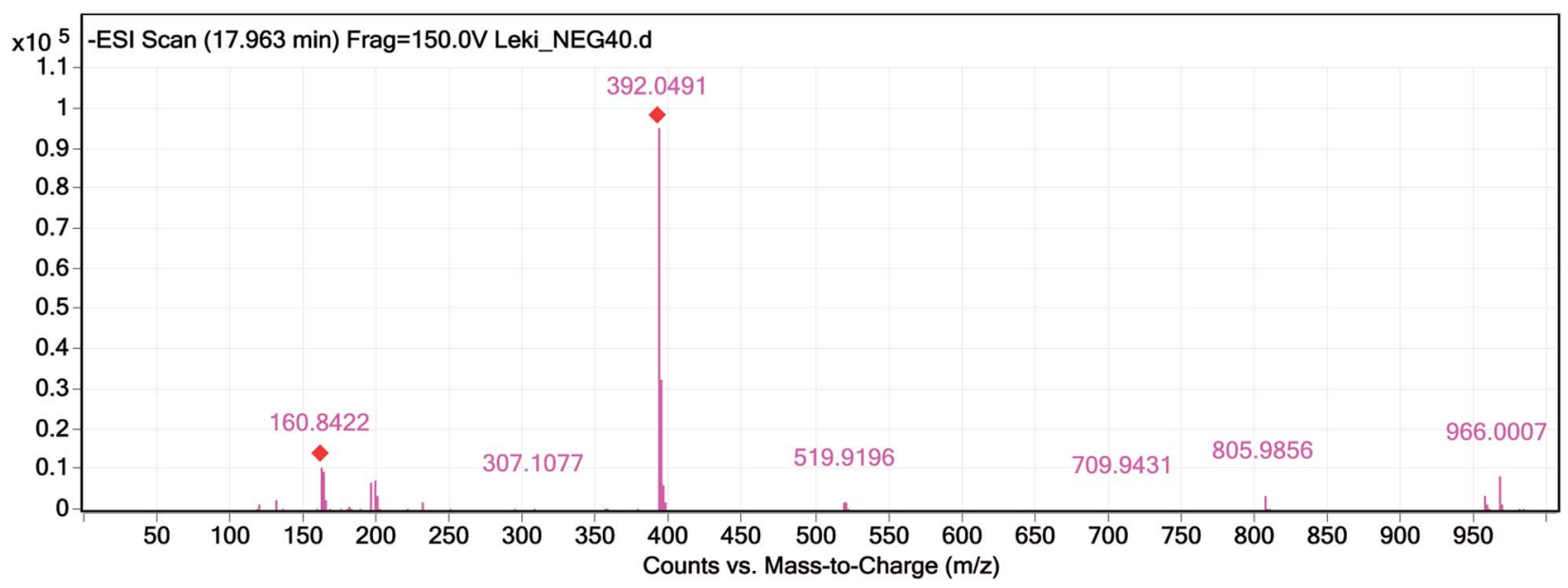

Fig. 6 Chromatogram DAD of indapamide (6) and dihydralazine (1) and their degradation product $(2-5,7)$ in borate buffer of $\mathrm{pH} 10(\mathrm{~A})$; negative ion ESI LC-MS of degradation product 2 of indapamide (B); negative ion ESI LC-MS of degradation product 5 of indapamide (C); CID off set $10 \mathrm{~V}$.

chromatogram and mass spectrum were presented in Fig. 6A and B. The proposed degradation pathway including this new degradation product was shown in Fig. 7.
Besides, next degradation product of indapamide was detected as an ion of $\mathrm{m} / \mathrm{z} 392.05$ and identified as 4chloro-3-(formylsulfamoyl)- $N$-(2-methyl-2,3-dihydro- $1 H$-indol-1- 
yl)benzamide (Table 1). Respective LC-DAD chromatogram and mass spectrum were presented in Fig. 6A and C. It was solely detected in the mixture of indapamide with dihydralazine after stressing with borate buffer of $\mathrm{pH} 10$. At the same time, this formate adduct was not observed in other samples from our experiments. Therefore, it was not formed due to the presence of formate ions in the mobile phase used for our LC separation. Thus, a new way of indapamide degradation could be proposed (Fig. 8).

\subsection{Validation of HPLC method}

A simple, isocratic HPLC method was developed for simultaneous determination of indapamide and dihydralazine in the presence of their degradation products with satisfactory retention times and peak shapes (Fig. 9A). It is worth mentioning that any similar report has not been described in the literature so far. Respective chromatograms showed that the peaks of indapamide and dihydralazine were free from interferences of the degradation products, confirming selectivity of the method (Fig. 9B).

Resistance of the method to small changes in analytical parameters, i.e. acetonitrile content $(30 \pm 2 \%)$, flow rate $(1.4 \pm$ $\left.0.2 \mathrm{~mL} \mathrm{~min}^{-1}\right)$, detection wavelength $(228 \pm 3 \mathrm{~nm})$ and column temperature $\left(22 \pm 2{ }^{\circ} \mathrm{C}\right)$ was examined. Uniformity of the obtained peak areas confirmed the robustness of the method. However, the calculated values of peak symmetry of indapamide indicated sensitivity of the method to changes of detection wavelength. As far as dihydralazine was concerned, the method was sensitive to changes of acetonitrile content in the mobile phase and flow rate of the mobile phase.

The quantitative method was found to be linear over the concentration range of $10-60 \mu \mathrm{g} \mathrm{mL}{ }^{-1}$ for both drugs, with average $R^{2}$ of 0.9992 for indapamide and 0.9990 for dihydralazine. The calculated LOD and LOQ were $1.81 \mu \mathrm{g} \mathrm{mL}^{-1}$ and $5.50 \mu \mathrm{g} \mathrm{mL}^{-1}$ for indapamide, and $1.69 \mu \mathrm{g} \mathrm{mL} \mathrm{md}^{-1}$ and $5.13 \mu \mathrm{g}$ $\mathrm{mL}^{-1}$ for dihydralazine. The RSD values in the range 0.25$1.52 \%$ for indapamide and $0.61-1.32 \%$ for dihydralazine (the

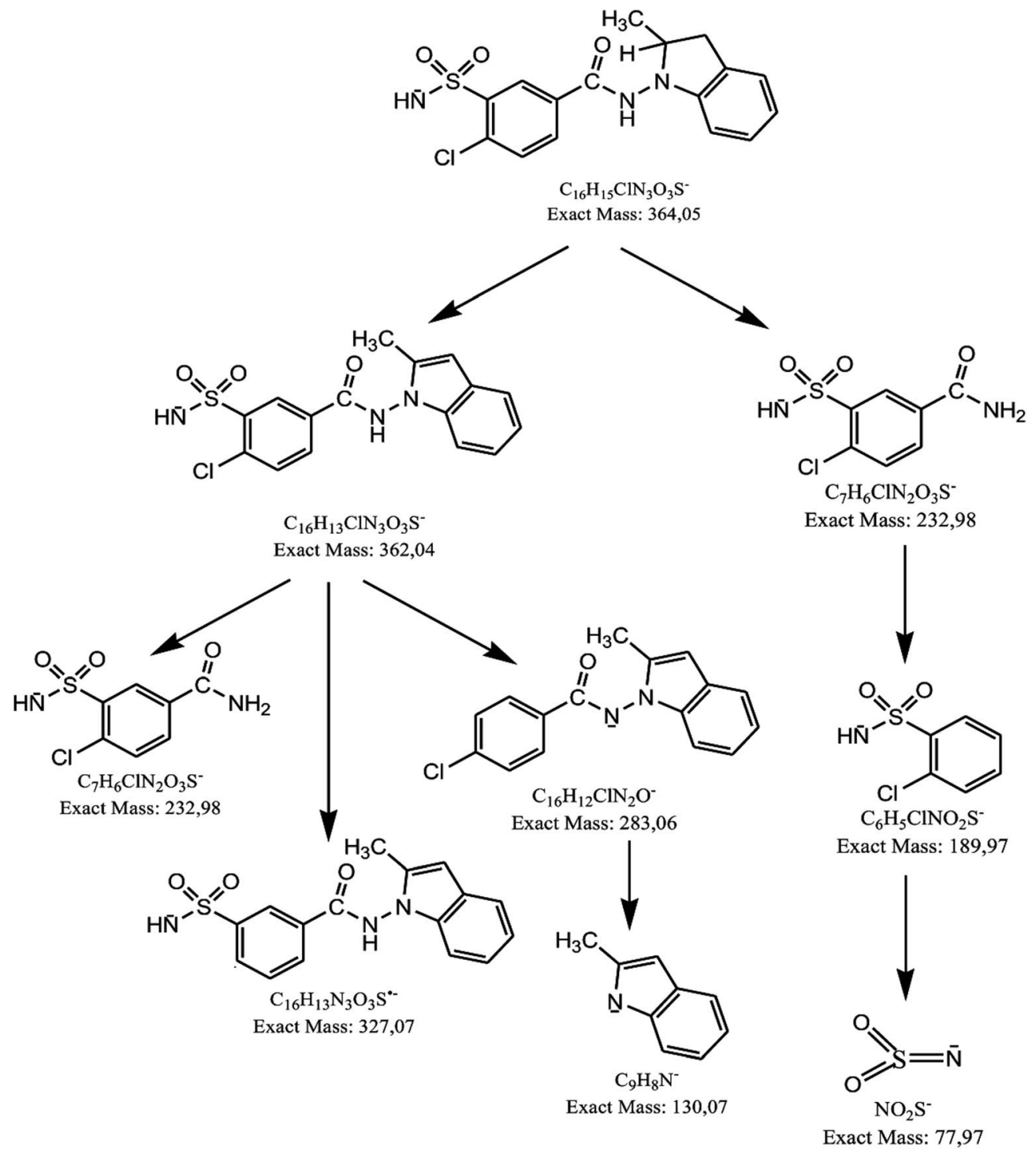

Fig. 7 Proposed degradation pathway of indapamide in a solid state and solutions. 


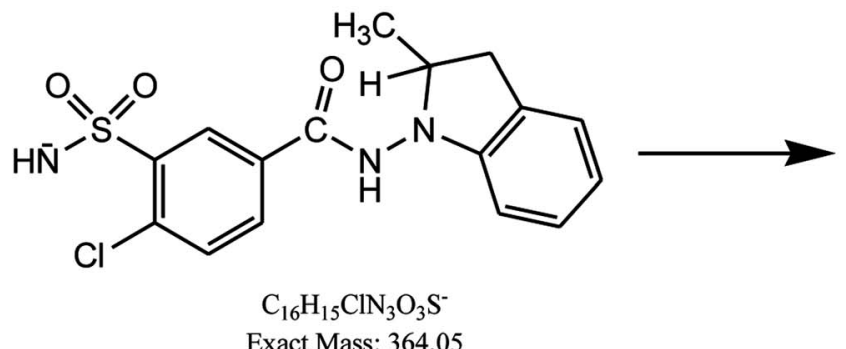

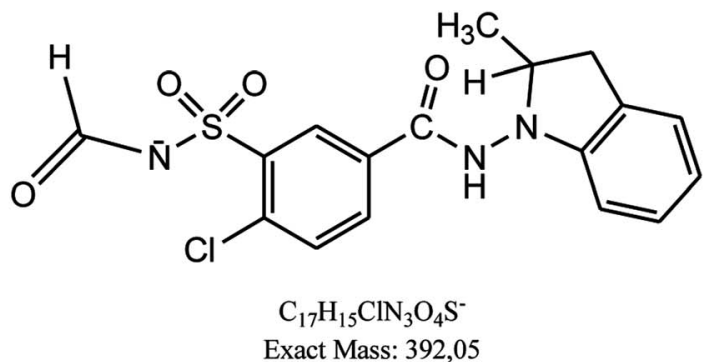

Fig. 8 Degradation of indapamide in borate buffer of $\mathrm{pH} 10$ in presence of dihydralazine.

one-day precision), and $\mathbf{0 . 8 5}-\mathbf{1 . 9 6 \%}$ for indapamide and $0.82-$ $1.93 \%$ for dihydralazine (the inter-day precision) were obtained. Accuracy of the method was confirmed by determining the both drugs in the powdered tablets. Recovery values were obtained in the range $99.66-100.72 \%$ for indapamide and $98.72-101.13 \%$ for dihydralazine (Table 2).

The chromatograms obtained for the samples of powdered tablets showed that the peaks of interest were free from

(A)

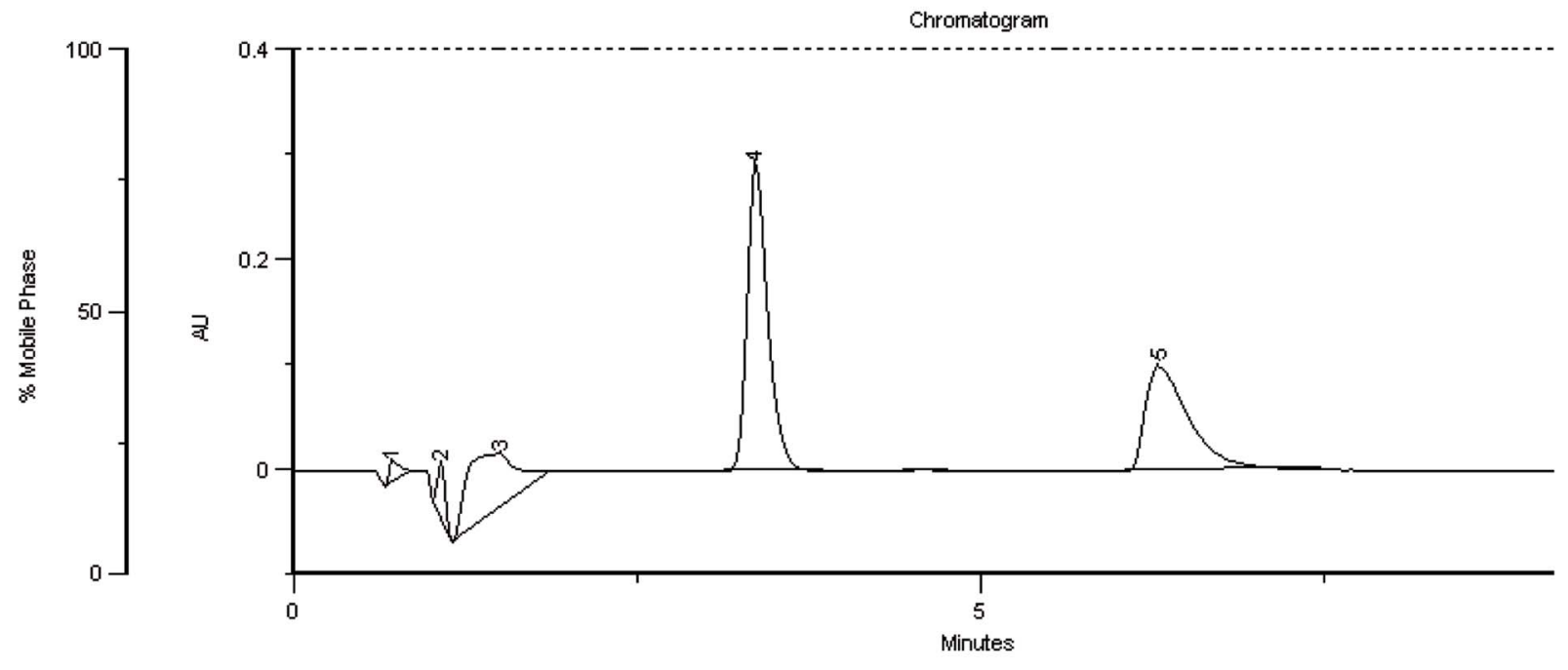

(B)

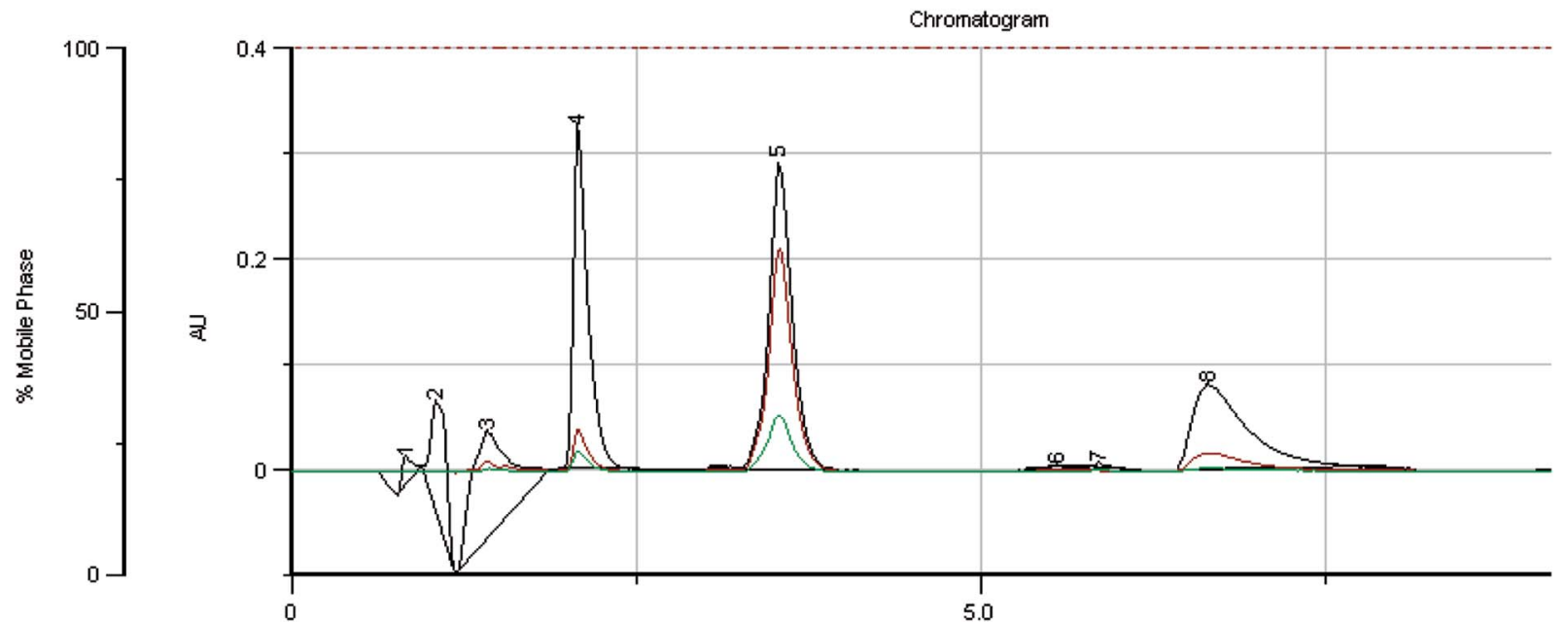

Fig. 9 HPLC chromatograms for simultaneous determination of indapamide (4) and dihydralazine (5) in the calibration solutions (A); chromatogram of indapamide (5) and dihydralazine (8) in presence of their degradation products $(4,6,7)(B)$. 
Table 2 Validation of HPLC method for simultaneous determination of indapamide and dihydralazine

\begin{tabular}{lll}
\hline Parameter & Indapamide & Dihydralazine \\
\hline Linearity range $\left(\mu \mathrm{g} \mathrm{mL}{ }^{-1}\right)$ & $10-60$ & $10-60$ \\
Slope & 85739 & 727036 \\
SD of slope & 6986 & 3097 \\
Intercept & 2333333 & -2166667 \\
SD for intercept & 471404 & 322678 \\
$R^{2}$ & 0.9992 & 0.9990 \\
SD of $R^{2}$ & 0.00047 & 0.00037 \\
LOD $\left(\mu g \mathrm{~mL}^{-1}\right)$ & 1.81 & 1.69 \\
LOQ $\left(\mu \mathrm{g} \mathrm{mL}^{-1}\right)$ & 5.50 & 5.13 \\
Accuracy $(\%$ recovery) & $99.66-100.72$ & $98.72-101.13$ \\
Precision $(\mathrm{RSD})$ & & \\
Intra-day & $0.25-1.52$ & $0.61-1.32$ \\
Inter-day & $0.85-1.96$ & $0.82-1.93$ \\
Retention time (min) & 3.58 & 6.58 \\
Asymmetry factor & 1.33 & 1.75 \\
& &
\end{tabular}

interferences of excipients, confirming selectivity of the method once more.

\subsection{Percentage levels of degradation at high temperature/ high humidity}

According to the literature, the highest degradation of indapamide (ca. $5 \%$ ) occurred at $50{ }^{\circ} \mathrm{C} / 80 \% \mathrm{RH}$ after 1 month. ${ }^{13}$ In the present study, indapamide showed lower degradation equal $1.05 \%$ at $70{ }^{\circ} \mathrm{C} / 80 \% \mathrm{RH}$ after 2 months. However, in the mixture with dihydralazine, an increase of indapamide degradation to $14.96 \%$ was observed (Table 3 ). Thus, combining indapamide with dihydralazine in fixed-dose formulations seemed to be unfavorable from the point of its chemical stability. At the same time, the present study showed that dihydralazine as an individual was sensitive to high temperature/high humidity (21.68\% of degradation). However, mixing it with indapamide did not affect its stability (Table 3). Therefore, the combined formulations of indapamide and dihydralazine could be

Table 3 Percentage levels of degradation of indapamide and dihydralazine under high temperature/high humidity and UV/VIS light

\begin{tabular}{|c|c|c|c|c|}
\hline \multirow[b]{3}{*}{ Conditions } & \multicolumn{4}{|c|}{ Level of degradation [\%] } \\
\hline & \multicolumn{2}{|c|}{ Indapamide } & \multicolumn{2}{|c|}{ Dihydralazine } \\
\hline & Individual & Mixture & Individual & Mixture \\
\hline \multicolumn{5}{|c|}{ Degradation in a solid state } \\
\hline $70^{\circ} \mathrm{C} / 80 \% \mathrm{RH}$ & 1.05 & 14.69 & 21.68 & 26.15 \\
\hline $1 \mathrm{ICH}^{a}$ & 1.76 & 1.87 & 1.45 & 5.98 \\
\hline $3 \mathrm{ICH}^{a}$ & 3.86 & 3.95 & 8.62 & 23.14 \\
\hline $6 \mathrm{ICH}^{a}$ & 7.15 & 8.23 & 25.78 & 48.76 \\
\hline \multicolumn{5}{|c|}{ Degradation in solutions } \\
\hline $1 \mathrm{ICH}^{a}$ & 17.52 & 17.97 & 2.78 & 21.08 \\
\hline $3 \mathrm{ICH}^{a}$ & 32.38 & 34.15 & 12.98 & 41.15 \\
\hline $6 \mathrm{ICH}^{a}$ & 67.16 & 69.88 & 100.0 & 100.0 \\
\hline
\end{tabular}

${ }^{a} 1 \mathrm{ICH}=18902 \mathrm{~kJ} \mathrm{~m}^{-2} ; 3 \mathrm{ICH}=56706 \mathrm{~kJ} \mathrm{~m}^{-2} ; 6 \mathrm{ICH}=113412 \mathrm{~kJ} \mathrm{~m}^{-2}$. manufactured, but high protection from high temperature and high humidity should be provided.

\subsection{Percentage levels of photodegradation}

According to the literature, the lack of photodegradation of indapamide in a solid state $\mathrm{s}^{7,12}$ or $100 \%$ of degradation of indapamide in methanolic solution ${ }^{10}$ were reported. Present experiment showed that indapamide in a solid state was rather resistant to the light impact. After irradiation with energy equal $18902 \mathrm{~kJ} \mathrm{~m}^{-2}$, the level of degradation of indapamide was determined as $1.76 \%$. When higher doses of light were used, degradation of indapamide at the levels 3.86 and $7.15 \%$ was shown (Table 3).

In addition, the FT-IR spectrum of the stressed indapamide did not show significant changes in comparison with the spectrum of the non stressed substance (Fig. 2C). However, when methanolic solution of indapamide was irradiated with energy equal $18902 \mathrm{~kJ} \mathrm{~m}^{-2}, 17.52 \%$ degradation of indapamide was observed. When higher doses of light were used, degradation of indapamide at the levels 32.38 and $67.16 \%$ occurred (Table 3). Bearing in mind the percentage levels of degradation, dihydralazine did not significantly increase photo-sensitivity of indapamide.

Of the two, individual dihydralazine was shown to be more sensitive to the light impact than indapamide with degradation in a solid state of $1.45 \%, 8.62 \%$ and $25.78 \%$ after irradiation with energy equal $18902 \mathrm{~kJ} \mathrm{~m}^{-2}, 56706 \mathrm{~kJ} \mathrm{~m}^{-2}$ and $113412 \mathrm{~kJ}$ $\mathrm{m}^{-2}$, respectively. In addition, the FT-IR spectrum of the stressed dihydralazine showed significant changes in comparison with the spectra of the non stressed drug (Fig. 3C). In methanolic solutions, respective levels of degradation were determined as $2.78 \%, 12.98 \%$ and $100 \%$. Moreover, dihydralazine in presence of indapamide underwent higher degradation than as an individual substance, even under lower doses of light. In a solid state the levels of degradation increased to 5.98 vs. $1.45 \%, 23.14$ vs. $8.62 \%$ and 48.76 vs. $25.78 \%$ while in solutions to 21.08 vs. $2.78 \%$ and 41.15 vs. $12.98 \%$ of degradation, under energy equal $18902 \mathrm{~kJ} \mathrm{~m}^{-2}$ and $56706 \mathrm{~kJ} \mathrm{~m}^{-2}$, respectively. These results allowed the conclusion that indapamide increased sensitivity of dihydralazine to light (Table 3). Thus, the combined formulations of indapamide and dihydralazine could be manufactured only when high protection from UV/VIS light is provided.

\subsection{Percentage levels of degradation in different $\mathbf{p H}$}

According to the literature, the highest degradation of indapamide occurred in $1 \mathrm{M} \mathrm{HCl}$ and $1 \mathrm{M} \mathrm{NaOH}(20.80 \%$ and $17.50 \%$, respectively). ${ }^{7}$ At the same time, there is not any report concerning degradation of indapamide in buffers of different $\mathrm{pH}$ values. Our experiments showed that indapamide was prone to degradation in $1 \mathrm{M} \mathrm{HCl}(11.08 \%)$, in borate buffer of $\mathrm{pH} 10$ $(21.27 \%)$ and in $1 \mathrm{M} \mathrm{NaOH}(16.18 \%)$. On the other hand, degradation of indapamide did not increase extensively in the presence of dihydralazine (Table 4).

As far as dihydralazine was concerned, the present study showed its stability in acidic environment $(1.32 \%$ of 
Table 4 Percentage degradation at different $\mathrm{pH}$ and kinetic parameters of indapamide

\begin{tabular}{|c|c|c|c|c|c|}
\hline Stress conditions & $\begin{array}{l}\text { Level of } \\
\text { degradation [\%] }\end{array}$ & Linear equation $y=a x+b$ & $R^{2}$ & $k\left[\mathrm{~s}^{-1}\right]$ & $t_{0.5}[\mathrm{~h}]$ \\
\hline \multicolumn{6}{|l|}{ Indapamide } \\
\hline Buffer pH 4 & 2.15 & - & - & - & - \\
\hline Buffer pH 7 & 2.15 & - & - & - & - \\
\hline Buffer pH 10 & 21.27 & $y=-0.0005 x+4.7965$ & 0.7207 & $1.92 \times 10^{-5}$ & 10.03 \\
\hline \multicolumn{6}{|c|}{ Indapamide in the mixture with dihydralazine } \\
\hline $1 \mathrm{M} \mathrm{HCl}$ & 12.42 & $y=-0.0003 x+4.0893$ & 0.7872 & $1.15 \times 10^{-5}$ & 16.74 \\
\hline Buffer pH 4 & 2.87 & - & - & - & - \\
\hline Buffer pH 7 & 2.86 & - & - & - & - \\
\hline Buffer pH 10 & 23.31 & $y=-0.0011 x+4.1307$ & 0.9388 & $4.22 \times 10^{-5}$ & 4.56 \\
\hline $1 \mathrm{M} \mathrm{NaOH}$ & 17.08 & $y=-0.0007 x+4.1016$ & 0.9314 & $2.69 \times 10^{-5}$ & 7.16 \\
\hline
\end{tabular}

degradation in $1 \mathrm{M} \mathrm{HCl}$ and $4.98 \%$ of degradation in buffer of $\mathrm{pH}$ 4). At the same time, high sensitivity of dihydralazine to $1 \mathrm{M}$ $\mathrm{NaOH}$ and to buffers of $\mathrm{pH} 7$ and 10 was confirmed $(100 \%$, $38.55 \%$ and $74.06 \%$ of degradation, respectively). Quite new conclusion was that dihydralazine in the presence of indapamide degraded to a greater extent in $1 \mathrm{M} \mathrm{HCl}$ (3.49\%), in buffer of $\mathrm{pH} 4(7.76 \%)$ and in buffer of $\mathrm{pH} 10$ (89.24\%). At $\mathrm{pH} 7$, the impact of indapamide on degradation of dihydralazine was not observed (Table 5).

\subsection{Kinetics}

At some conditions, the level of degradation of indapamide and dihydralazine was too low to obtain reliable kinetic data. Thus, kinetic parameters were calculated only when the levels of degradation of the drugs were at least $10 \%$ after $300 \mathrm{~min}$. The concentrations of drugs remaining after each time point were calculated from respective linear regression equations and represented in terms of mean after triplicate analysis. Then, the concentrations $(C)$ or $\ln (C)$ were plotted against time to determine the reaction order of degradation. For the both drugs, stronger correlations (higher $R^{2}$ values) were obtained for semilogarithmic plots, indicating that degradation of indapamide and dihydralazine followed the first order kinetics. From the slopes of these semi-logarithmic plots, the observed rate constant $(k)$ and degradation time of $50 \%$ substance $\left(t_{0.5}\right)$ were calculated.

It was shown that indapamide degraded in different $\mathrm{pH}$ with $k$ values at the levels of $10^{-5} \mathrm{~s}^{-1}$. The shortest $t_{0.5}(\mathrm{ca} .10 \mathrm{~h})$ was obtained in $1 \mathrm{M} \mathrm{NaOH}$ and in buffer of $\mathrm{pH} 10$. However, in the presence of dihydralazine, degradation of indapamide was observed as much faster reaction with $t_{0.5}$ of 4.56-7.16 h (Table 4). As was described above, in the literature there is not any report involving kinetic parameters for indapamide degradation. Thus, the results presented here supplemented the literary resources in this area. As far as dihydralazine was concerned, the $k$ values of degradation processes were obtained at the levels of $10^{-5} \mathrm{~s}^{-1}$ to $10^{-4} \mathrm{~s}^{-1}$. The degradation rate increased with the $\mathrm{pH}$ increase when the $\mathrm{pH}$ of the solution was in basic part. These results indicated specific basic catalysed effects on the degradation of dihydralazine. The shortest $t_{0.5}(0.42 \mathrm{~h})$ was calculated for degradation in $1 \mathrm{M}$ $\mathrm{NaOH}$. At the same time, the presence of indapamide significantly shortened the $t_{0.5}$ value for degradation of dihydralazine in borate buffer of $\mathrm{pH} 10$ (Table 5).

Table 5 Percentage degradation at different $\mathrm{pH}$ and kinetic parameters of dihydralazine

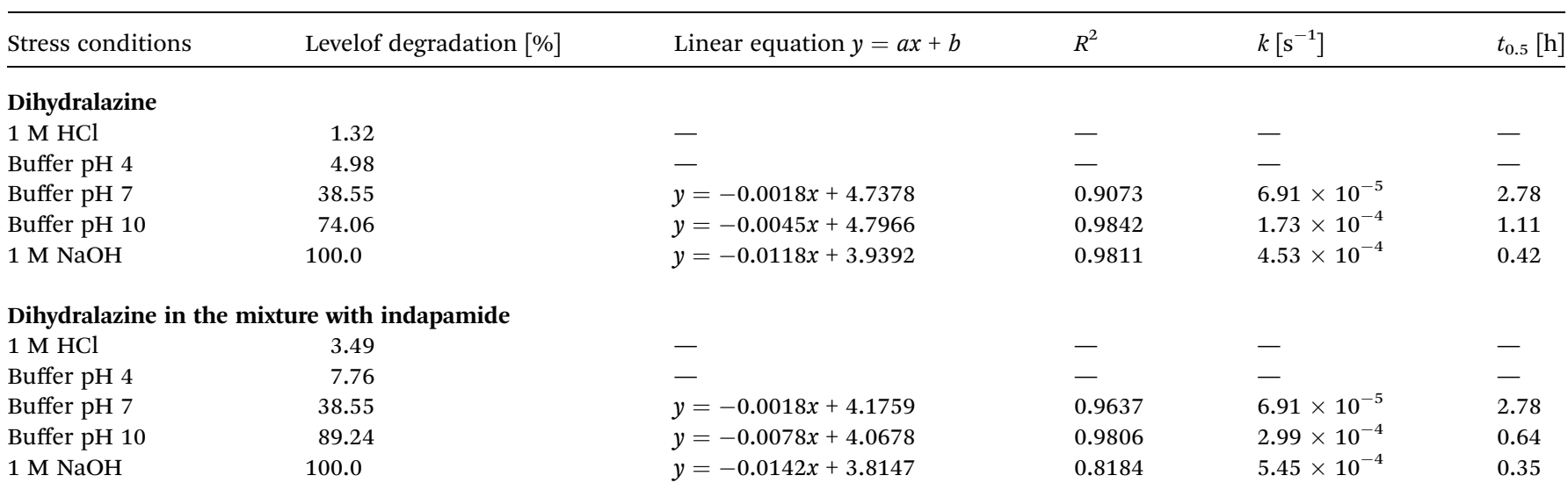




\section{Conclusions}

Indapamide in a solid state is resistant to high temperature/ high humidity but sensitive to UV/VIS light while dihydralazine is sensitive to both stressors. In solutions, indapamide is sensitive to strong acidic and strong basic conditions while dihydralazine degrades intensively at $\mathrm{pH} \geq 7$. Generally, percentage degradation of drugs in their mixtures is greater than that of individual drugs under the same stress conditions.

Increased sensitivity of the both active substances to stressors and potent chemical interactions between them were confirmed by detection of new degradation products of indapamide, i.e. 4-chloro-3-sulfamoylbenzamide and 4-chloro-3(formylsulfamoyl)- $N$-(2-methyl-2,3-dihydro- $1 H$-indol-1-yl) benzamide. Such degradation products of indapamide were not described in the literature so far.

Thus, the current knowledge about degradation of indapamide as well as of dihydralazine was significantly improved. Such results may be the starting point for new studies on toxicity of new degradation products and then, for qualifying them as new related substances in pharmacopoeial monographs. These data may also serve as a starting point for designing new antihypertensive formulations containing indapamide and dihydralazine. These two active substances can be combined to fixed-dose formulations because of their complementary actions against hypertension. However, possibility of chemical interactions between these drugs, i.e. their accelerated degradation and generation of new degradation products in the mixture, was clearly shown. Thus, the necessity of highly protecting indapamide and dihydralazine from high temperature, high humidity and UV/VIS light was proved.

\section{Conflicts of interest}

There are no conflicts of interest to declare.

\section{References}

1 M. Inaba, Y. Noguchi, T. Yamamoto, T. Imai, M. Hatano, S. Yagi and S. Katayama, Hypertens. Res., 2004, 27, 141-145. 2 N. S. Skolnik, J. D. Beck and M. Clark, Am. Fam. Physician, 2000, 61, 3049-3056.
3 H. K. H. Pannu, M. P. Mahajan and S. D. Sawant, Der Pharma Chem., 2012, 4, 996-1002.

4 J. B. Pai, K. S. A. Sathish, B. Gopinath and G. Chenna, Int. J. PharmTech Res., 2011, 3, 1482-1487.

5 J. Joseph, B. Philip and M. Sundarapandian, Int. J. Pharmacol. Pharm. Sci., 2011, 3, 288-293.

6 R. Tiwari, A. Jain, D. Maliwal and E. Toppo, Asian J. Pharm. Clin. Res., 2012, 5, 50-53.

7 A. Fernández-Carballido, E. Barcia, D. Córdoba-Díaz, M. Córdoba-Díaz and S. Negro, Curr. Pharm. Anal., 2014, 10, 10-19.

8 C. S. Satpute, P. Pagare, V. M. Jadhav and V. J. Kadam, Res. J. Pharm. Technol., 2013, 6, 1217-1224.

9 T. M. Kalyankar, P. K. Khadkutkar and R. B. Kakde, Int. J. Res. Ayurveda Pharm., 2012, 3, 729-732.

10 A. El-Gindy, M. W. Nassar, K. A. S. Attia, H. H. Abu-Seada and M. El-Ghandour, J. Liq. Chromatogr. Relat. Technol., 2014, 37, 696-712.

11 G. Rashmita, T. Ramesh and M. Ramesh, Der Pharma Chem., 2013, 5, 347-352.

12 H. Jogia, U. Khandelwal, T. Gandhi, S. Singh and D. Modi, J. AOAC Int., 2010, 93, 108-115.

13 K. A. M. Attia, M. W. I. Nassar, M. M. K. El-Din, M. K. Sharaf, A. A. Mohamad and M. M. Y. Kaddah, Anal. Methods, 2016, 8, 1836-1851.

14 ICH Topic Q1B, Photostability Testing of New Active Substances and Medicinal Products, 2006.

15 S. K. Raul, B. V. Ravi Kumar, A. K. Pattnaik and N. N. Rao, Int. J. Pharm., 2013, 3, 116-121.

16 A. Gumieniczek, J. Galeza, T. Mroczek, K. Wojtanowski, K. Lipska and R. Pietras, Chromatographia, 2018, 81, 11471162.

17 B. Q. Che, Acta Pharmacol. Sin., 2004, 39, 618-620.

18 P. F. Jin, Y. T. Kuang, D. Zou, X. Hu, W. Q. Jiang and X. J. Wu, Chin. Pharm. J., 2011, 46, 152-155.

19 A. Gumieniczek, J. Galeza, A. Berecka, T. Mroczek, K. Wojtanowski, K. Lipska and J. Skarbek, European Pharmacopeia, Council of Europe, Strasbourg, 9th edn, 2016.

20 ICH Topic Q1A(R2), Stability Testing of New Drug Substances and Products, 2003. 